\title{
Titanium dioxide/graphene oxide composite and its application as an anode material in non-flammable electrolyte based on ionic liquid and sulfolane
}

\author{
Beata Kurc $^{1}$ - Katarzyna Siwińska-Stefańska ${ }^{2}$ Pawel Jakóbczyk ${ }^{1} \cdot$ Teofil Jesionowski $^{2}$
}

Received: 19 October 2015 /Revised: 20 March 2016 / Accepted: 24 March 2016 /Published online: 12 April 2016

(C) The Author(s) 2016. This article is published with open access at Springerlink.com

\begin{abstract}
A composite of aminosilane-grafted $\mathrm{TiO}_{2}(\mathrm{TA})$ and graphene oxide (GO) was prepared via a hydrothermal process. The $\mathrm{TiO}_{2} /$ graphene oxide-based (TA/GO) anode was investigated in an ionic liquid electrolyte $(0.7 \mathrm{M}$ lithium bis(trifluoromethanesulfonyl)imide $\left(\operatorname{LiNTf}_{2}\right)$ ) in ionic liquid ( $N$-methyl- $N$-propylpyrrolidinium bis(trifluoromethanesulfonyl)imide $\left(\mathrm{MPPyrNTf}_{2}\right)$ ) at room temperature and in sulfolane $(1 \mathrm{M}$ lithium hexafluorophosphate $\left(\mathrm{LiPF}_{6}\right)$ in tetramethylene sulfolane (TMS)). Scanning and transmission electron microscopy (SEM and TEM) observations of the anode materials suggested that the electrochemical intercalation/deintercalation process in the ionic liquid electrolyte with vinylene carbonate (VC) leads to small changes on the surface of TA/GO particles. The addition of $\mathrm{VC}$ to the electrolyte $\left(0.7 \mathrm{M} \mathrm{LiNTf}_{2}\right.$ in MPPyrNTf $f_{2}+10 \mathrm{wt} . \% \mathrm{VC}$ ) considerably increases the anode capacity. Electrodes were tested at different current regimes in the range $5-50 \mathrm{~mA} \mathrm{~g}^{-1}$. The capacity of the anode, working at a low current regime of $5 \mathrm{~mA} \mathrm{~g}^{-1}$, was ca. $245 \mathrm{~mA} \mathrm{~g}^{-1}$, while a current of $50 \mathrm{~mA} \mathrm{~g}^{-1}$ resulted in a capacity of $170 \mathrm{~mA} \mathrm{~g}^{-1}$. The decrease in anode capacity with increasing current rate was interpreted as the result of kinetic limits of electrode
\end{abstract}

Katarzyna Siwińska-Stefańska

katarzyna.siwinska-stefanska@put.poznan.pl

1 Institute of Chemistry and Electrochemistry, Faculty of Chemical Technology, Poznan University of Technology, Berdychowo 4, PL-60965 Poznan, Poland

2 Institute of Chemical Technology and Engineering, Faculty of Chemical Technology, Poznan University of Technology, Berdychowo 4, PL-60965 Poznan, Poland operation. A much lower capacity was observed for the system TA/GO $1 \mathrm{M} \mathrm{LiPF}_{6}$ in TMS + $10 \mathrm{wt} . \% \mathrm{VC} \mid \mathrm{Li}$.

Keywords Titania/GO composite $\cdot$ Hydrothermal process · Anode material $\cdot$ Non-flammable electrolyte $\cdot$ Ionic liquid

\section{Introduction}

Lithium-ion batteries (LIBs) have been widely applied as a power source for portable electronics, stationary energy storage systems, and electric vehicles, due to their high theoretical capacity, long cycle life, wide application temperature range, low cost, good safety performance, and environmental friendliness compared with other types of batteries [1-7].

The properties of LIBs greatly depend on the electrode materials used [7, 8]. Graphite is the most widely used anode material in commercial Li-ion batteries. The theoretical capacity of graphite is estimated to be $372 \mathrm{mAh} \mathrm{g}^{-1}$. Structural deformation, initial loss of capacity, and electrical disconnection are the chief disadvantages of the graphite electrode, which limit its application and development [2, 3, 9-12]. Among potential candidates to replace the commonly used carbon (graphite) as anode material, titanium dioxide as well as titania-based materials have been investigated. Titanium dioxide has been recognized as one of the promising anode materials for LIBs among transition metal oxides, by virtue of its attractive properties which include low cost, high chemical stability, low solubility in organic solution, eco-friendliness, high energy density, and easy availability $[5,7,10,12]$. In addition, intercalation/deintercalation of titania offers good cycling stability, low volume expansion during charging/ discharging, and increased safety by virtue of the high 
Li-insertion potential $\left(1.6-1.8 \mathrm{~V}\right.$ vs. $\left.\mathrm{Li}^{+} / \mathrm{Li}\right)[1,3$, 12-14]. Unfortunately, in comparison with conventional anode materials, $\mathrm{TiO}_{2}$ has a relatively low theoretical capacity of around $335 \mathrm{mAh} \mathrm{g}^{-1}$, and intrinsically slow transport kinetics for both electrons and $\mathrm{Li}$ ions, which prevents this material from achieving optimal electrochemical performance $[1,5,8,13,14]$. The electrochemical application of titania depends strongly on its crystal structure, crystallite size, surface area, and thermal stability. It is well known that anatase $\mathrm{TiO}_{2}$ is more electrochemically active than the thermodynamically stable rutile $\mathrm{TiO}_{2}$. Anatase and rutile present a low specific capacity of $167.5 \mathrm{mAh} \mathrm{g}^{-1}[1,5,13,14]$.

Many types of hybrid materials containing carbon and electroactive materials have attracted considerable interest for use in LIBs, because of their improved rate capability and enhanced cyclic performance by virtue of their superior electrical conductivity, chemical tolerance, broad electrochemical window, and high surface area - see Table 1 [15-22].

In this work, a composite of aminosilane-grafted $\mathrm{TiO}_{2}$ and graphene oxide was prepared via a hydrothermal process. The $\mathrm{TiO}_{2}$ /graphene oxide-based (TA/GO) anode was investigated in an ionic liquid electrolyte (0.7 M lithium bis(trifluoromethanesulfonyl)imide ( $\left.\mathrm{LiNTf}_{2}\right)$ in ionic liquid ( $N$-methyl- $N$-propylpyrrolidinium bis(trifluoromethanesulfonyl)imide $\left.\left(\operatorname{MPPyrNTf}_{2}\right)\right)$ at room temperature and in sulfolane $(1 \mathrm{M}$ lithium hexafluorophosphate $\left(\mathrm{LiPF}_{6}\right)$ in tetramethylene sulfolane (TMS)). Electrochemical experiments showed that a new type of TA/GO composite exhibited excellent electrochemical performance as the anode material in a Li-ion battery.

\section{Experimental}

\section{Materials}

Titanium tetraisopropoxide (TTIP, Sigma-Aldrich), propan-2-ol (IPA, Chempur), ammonia (Chempur), methanol ( $\mathrm{MeOH}$, Chempur), $N$-2-(aminoethyl)-3-aminopropyl-trimethoxysilane (AAPTS, Sigma-Aldrich), GO (Sigma-Aldrich), and ethanol (EtOH, Chempur) were used without any further purification.

Lithium foil (0.75 mm thick, Aldrich), $\mathrm{LiPF}_{6}$ (Aldrich), TMS (Aldrich), VC ( Aldrich), $\operatorname{LiNTf}_{2}$ (Fluka), carbon black (CB, Alfa Aesar), poly(vinylidene fluoride) (PVdF, Fluka), and $N$-methyl-2-pyrrolidinone (NMP, Fluka) were used as received from suppliers. $N$-methyl- $N$-propylpyrroldinium bromide (MPPyrBr) was obtained by reacting $\mathrm{N}$ methylpyrrolidinium (Aldrich) with bromopropane (Aldrich) in acetone. Precipitated white MPPyrBr crystals were decanted, washed five times with n-hexane, and dried under vacuum at $40{ }^{\circ} \mathrm{C}$. $N$-methyl- $N$-propylpyrrolidinium bis(trifluoromethanesulfonyl)imide (MPPyrNTf ${ }_{2}$ ) was obtained from MPPyrBr and $\mathrm{LiNTf}_{2}$ solution in an aqueous medium. The ionic liquid (IL) phase was separated from the aqueous $\mathrm{LiBr}$ solution, washed three times with water, and finally dried by evaporation in a vacuum at $50^{\circ} \mathrm{C}$ for $10 \mathrm{~h}$. The solid LiNTf $_{2}$ salt was dissolved in the liquid salt MPPyrNTf $\left(0.7 \mathrm{M}\right.$ solution of $\mathrm{LiNTf}_{2}$ in MPPyrNTf $\left.{ }_{2}\right)$ to obtain the $\mathrm{Li}^{+}$-containing ionic liquid $\left[\mathrm{Li}^{+}\right] \mathrm{m}[\mathrm{MPPyr}] \mathrm{n}\left[\mathrm{NTf}_{2}\right] \mathrm{z}$. The water content in the $\left[\mathrm{Li}^{+}\right] \mathrm{m}[\mathrm{MPPyr}] \mathrm{n}\left[\mathrm{NTf}_{2}\right] \mathrm{z}$ electrolyte, analyzed with a standard Karl Fischer titrant (Aldrich), was below $0.4 \mathrm{mg} \mathrm{H}_{2} \mathrm{O} \mathrm{L}^{-1}$. Vinylene carbonate was stored at a maximum temperature of $8{ }^{\circ} \mathrm{C}$ to prevent its spontaneous

Table 1 Electrochemical characteristics of different types of materials

\begin{tabular}{|c|c|c|c|}
\hline Materials & Preparation method & Capacity $/ \mathrm{mAh} \mathrm{g}^{-1}$ & Refs \\
\hline $\mathrm{TiO}_{2} /$ reduced graphene oxide & $\begin{array}{l}\text { Titanium tetrabutoxide and graphene oxide was } \\
\text { treated by hydrothermal synthesis. }\end{array}$ & 295 & [15] \\
\hline Sulfur-doped graphene-based nanosheets & $\begin{array}{l}\text { Graphene oxide and elemental sulfur was thermally } \\
\text { treated in a tubular furnace from room temperature to } 600{ }^{\circ} \mathrm{C} \text {. }\end{array}$ & 285 & {$[16]$} \\
\hline $\mathrm{TiO}_{2} /$ graphene nanosheets & $\begin{array}{l}\text { Graphene nanosheets (GNS) with } N \text {-methyl-2-pyrrolidine } \\
\text { (NMP) as dispersant was mixed with the anatase } \mathrm{TiO}_{2} \\
\text { nanoparticles, and then obtained hybrid was thermally } \\
\text { treated at } 200{ }^{\circ} \mathrm{C} \text {. }\end{array}$ & 120 & {$[17]$} \\
\hline $\mathrm{TiO}_{2} / \mathrm{RGO}$ nanocomposite & $\mathrm{GO}$ and anatase $\mathrm{TiO}_{2}$ was treated under the UV irradiation. & 310 & {$[18]$} \\
\hline Mesoporous $\mathrm{TiO}_{2}$ & $\begin{array}{l}\mathrm{TiO}_{2} \text { nanocrystals were prepared by a simple and fast hydrolytic } \\
\text { process, in the presence of tetrabutylammonium bromide surfactant. }\end{array}$ & 158 & [19] \\
\hline Nanosized $\mathrm{TiO}_{2}(\mathrm{~B})$ & $\begin{array}{l}\mathrm{TiO}_{2}(\mathrm{~B}) \text { powder was prepared via a solid-state reaction reported } \\
\text { by Feist and Davies. }\end{array}$ & 200 & {$[20]$} \\
\hline $\begin{array}{l}\text { Graphene-bonded and graphene-encapsulated } \\
\text { mesoporous } \mathrm{TiO}_{2}(\text { GMTMs) }\end{array}$ & $\begin{array}{l}\text { GMTMs was prepared by hydrothermal treatment and calcination } \\
\text { in an Ar atmosphere. }\end{array}$ & 170 & {$[21]$} \\
\hline $\begin{array}{l}\mathrm{TiO}_{2} \text { nanoparticles on nitrogen-doped } \\
\text { graphene }\left(\mathrm{TiO}_{2} / \mathrm{N}-\mathrm{rGO}\right)\end{array}$ & $\mathrm{TiO}_{2} / \mathrm{N}-\mathrm{rGO}$ was prepared by hydrothermal method. & 187 & {$[22]$} \\
\hline
\end{tabular}


polymerization. Electrolytes containing $\mathrm{VC}$ as a solid electrolyte interface (SEI)-forming additive (10 wt.\%) were prepared in a dry argon atmosphere in a glove box.

\section{Preparation of modified titania}

In the first step, titania powder (sample T) was synthesized by a modified sol-gel process, as described previously by the authors [23]. In a three-neck flask, TTIP was dissolved in IPA. Then, a catalyst (ammonia/deionized water mixture (1/ $4 v / v)$ ) was introduced into the solution at a constant rate of $2 \mathrm{~mL} \mathrm{~min}^{-1}$ using an ISM833A peristaltic pump (Ismatec) with vigorous stirring at room temperature. The milky reactive mixture was then vigorously stirred for $1 \mathrm{~h}$ using a high-speed stirrer of T25 Basic type (IKA Werke $\mathrm{GmbH}$ ) running at $1200 \mathrm{rpm}$. The colloidal suspension obtained was then placed in a SEL-I3 chamber drier (Memmert) at $105^{\circ} \mathrm{C}$ for $18 \mathrm{~h}$. The resulting alcogel was washed several times with deionized water and filtered to remove impurities. At the final stage, washed precipitation was dried by convection at $105^{\circ} \mathrm{C}$ for $6 \mathrm{~h}$ and then calcined at $600{ }^{\circ} \mathrm{C}$ for $2 \mathrm{~h}$ (Nabertherm). In the second step, the obtained titania powder was grafted with AAPTS-sample TA. Modification was performed using 1 wt. $\%$ of AAPTS (calculated for $100 \mathrm{~g}$ of $\mathrm{TiO}_{2}$ ) prepared in a $\mathrm{MeOH} /$ deionized water mixture $(4 / 1 v / v)$ and applying the socalled dry technique, described in detail in $[24,25]$. Titania was treated with AAPTS to obtain a positively charged surface, to enhance the interaction between titania and graphene oxide. The proposed method for preparing modified $\mathrm{TiO}_{2}$ is presented schematically in Fig. 1.

\section{Preparation of TA/GO composite}

Titania/graphene oxide composite was synthesized by the following hydrothermal process. Firstly, $2 \mathrm{~g}$ of modified titania was mixed with $20 \mathrm{~mL}$ of deionized water and $5 \mathrm{~mL}$ of GO suspension $\left(2 \mathrm{mg} \mathrm{mL}^{-1}\right)$. The obtained mixture was sonicated for $15 \mathrm{~min}$. Then, the resulting solution was separated by centrifugation for $20 \mathrm{~min}$ at $4000 \mathrm{rpm}$ (Centrifuge $5810 \mathrm{R}$, Eppendorf). Next, the wet TA/GO composite was dispersed in $40 \mathrm{~mL}$ of a deionized water/EtOH mixture $(1 / 1 v / v)$, placed in a Teflon-lined stainless steel reactor and thermally treated $\left(120{ }^{\circ} \mathrm{C}\right.$ for $\left.4 \mathrm{~h}\right)$. After that time, the obtained precipitate was naturally cooled to room temperature. The resulting gray powder was filtered, washed with deionized water several times, and dried at $60^{\circ} \mathrm{C}$ for $2 \mathrm{~h}$.

\section{Preparation of the electrolyte and electrode}

Electrolytes were obtained by dissolution of the $\mathrm{LiPF}_{6}$ solid salt in liquid TMS heated to ca. $35{ }^{\circ} \mathrm{C}$ (TMS is solid at room temperature). The electrolytes contained VC as the $S E I$-forming additive (10 wt.\%). Tested anodes were prepared on a copper foil (Hohsen, Japan) by a casting technique, from a slurry of graphite, $\mathrm{CB}$, and $\mathrm{PVdF}$ in NMP. The ratio of components was $\mathrm{TA} / \mathrm{GO} / \mathrm{CB} / \mathrm{PVdF}=85: 5: 10$ (by weight). After evaporation of the solvent (NMP) at $120^{\circ} \mathrm{C}$ in vacuum, a layer of the carbon electrode containing the active material (TA/GO), an electronic conductor (CB), and the binder (PVdF) was formed.

\section{Procedures and measurements}

Dispersive characteristics of the obtained materials were determined by a Zetasizer Nano ZS apparatus (Malvern Instruments Ltd), using the non-invasive back scattering method. The morphology and microstructure of the obtained samples were analyzed using a Jeol 1200 EX II transmission electron microscope, at an accelerating voltage of $100 \mathrm{kV}$. The structural properties of the synthesized materials, such as phase and crystallite size, were determined by the X-ray diffraction (XRD) method. XRD analysis was performed utilizing a TUR-M62 diffractometer with $\mathrm{Cu}$ $\mathrm{K} \alpha$ radiation $(\alpha=1.5418 \AA)$, Ni filtered. The patterns were obtained in step-scanning mode $\left(\Delta 2 \theta=0.04^{\circ}\right)$ over an

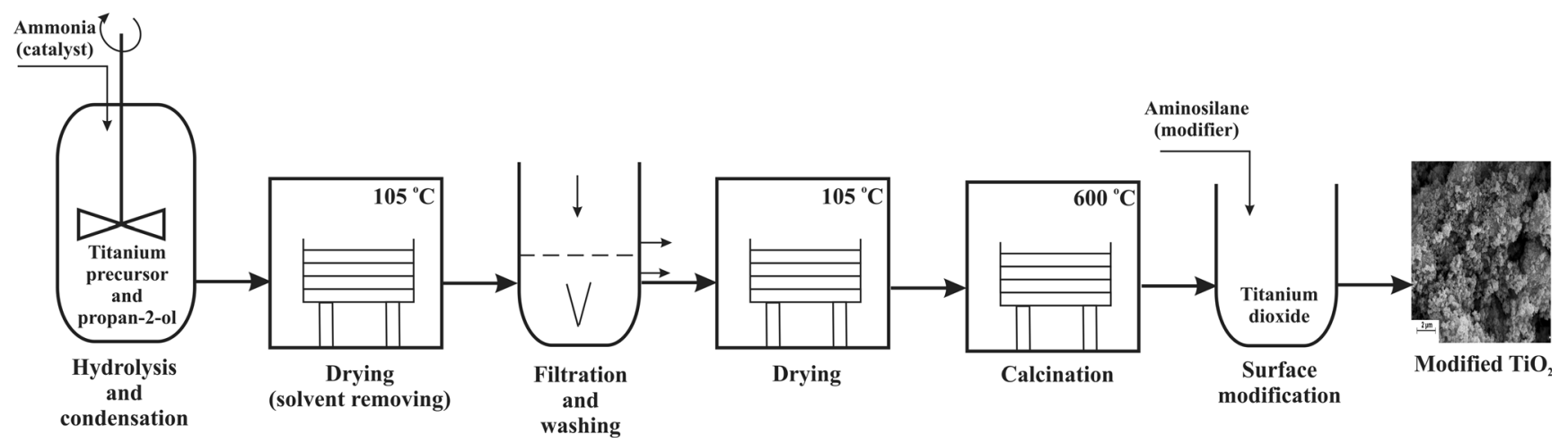

Fig. 1 Preparation of mesoporous modified titania 
angular range of $10-60^{\circ}$. The Scherrer equation [26], with (101) and (110) reflections of the anatase and rutile planes, respectively, was used to calculate crystallite size as well as to evaluate the relative content of anatase and rutile phases in the prepared samples. The surface area, average pore diameter, and total pore volume of the obtained materials were measured from the $\mathrm{N}_{2}$ adsorption/desorption isotherm via the Brunauer-Emmett-Teller (BET, for specific surface area) and Barrett-Joyner-Halenda (BJH, for pore volume and pore diameter) methods, using a ASAP 2020 porosimetry analyzer (Micromeritics Instrument Co.). Fourier transform infrared spectroscopy (FTIR) measurements were conducted on a Vertex 70 spectrophotometer (Bruker) at room temperature, to identify the characteristic groups present on the surface of the obtained materials. The samples were prepared by mixing with $\mathrm{KBr}$ and then pressing into small tablets. FTIR spectra were obtained in the transmission mode between 4000 and $400 \mathrm{~cm}^{-1}$.

Electrochemical properties of the cells were determined using electrochemical impedance spectroscopy $(E I S)$ and galvanostatic charging/discharging tests. Cycling measurements were taken with the use of the ATLAS 0461 MBI multichannel electrochemical system (Atlas-Sollich, Poland) at different current rates. Cyclic voltammetry for T, TA, and TA/GO anodes was carried out in the potential range $1.0-2.5 \mathrm{~V}$ vs. $\mathrm{Li}^{-} \mathrm{Li}^{+}$ with scan rates of $0.1,0.5$, and $0.8 \mathrm{mV} \mathrm{s}^{-1}$. Impedance spectra were obtained using a frequency response analyzer at a frequency range of $100 \mathrm{kHz}-10 \mathrm{mHz}$ at the open circuit potential and an amplitude of $10 \mathrm{mV}$.

Electrodes were separated by a glass microfiber GF/A separator (Whatmann, 0.4-0.6 mm thick), placed in an adopted Swagelok $^{\circledR}$ connecting tube. Typically, the mass of the electrodes was as follows: Li ca. $45 \mathrm{mg}\left(0.785 \mathrm{~cm}^{2}\right)$; T, TA, and TA/GO 3.0-4.0 mg. Cell assembly was performed in a glove box in a dry argon atmosphere.

Following the electrochemical measurements, the cells were disassembled and the graphite electrodes were washed with dimethyl carbonate (DMC) and dried in a vacuum at room temperature. The morphology of the electrodes and polymer electrolytes was observed by means of scanning electron microscopy (SEM) (Tescan Vega 5153) and TEM. All operations were carried out in a dry argon atmosphere in a glove box.

\section{Results and discussion}

\section{Dispersive and morphological properties}

The aim of the first stage of the study was to determine the dispersive and morphological properties of the materials obtained (Table 2, Fig. 2). The particle size distribution by volume contribution for sample Tobtained via the sol-gel method and calcined at $600{ }^{\circ} \mathrm{C}$ shows a monomodal band corresponding to primary agglomerates with diameters ranging from 190 to $712 \mathrm{~nm}$. The maximum volume contribution $(23.7 \%)$ comes from particles $396 \mathrm{~nm}$ in diameter. The polydispersity index of this sample is 0.109 .

Dispersive analysis of the modified TA and TA/GO samples showed that the surface modification of titanium dioxide with a silane coupling agent and synthesis of TA/GO composite leads to products characterized by not only the presence of particles of higher diameter but also a visible shift in the diameter of the particles with the maximum volume contribution toward higher diameter values, compared to the initial $\mathrm{TiO}_{2}$. Sample TA is characterized by a monomodal band with a diameter range of 190-955 nm. The TA/GO composite shows the presence of particles in two different diameter ranges (295-1110 and 4800-6440 nm). The maximum volume contributions, of 6.2 and $36.6 \%$, correspond respectively to particles and agglomerates 615 and $5560 \mathrm{~nm}$ in diameter.

TEM images of the obtained materials confirmed the dependencies of the dispersive properties (Fig. 2a-c). Additionally, these images show the irregular shape of the titania particles (Fig. 2a, b) as well as their efficient incorporation into the graphene oxide structure (Fig. 2c).

\section{Structural properties}

The structural properties of the obtained materials, such as phase and crystallite size, were determined by XRD (see Fig. 3). As shown in Fig. 3a, the $\mathrm{TiO}_{2}$ synthesized via the sol-gel method and calcined at $600{ }^{\circ} \mathrm{C}$ exhibits good crystallinity and a typical anatase and rutile structure, which is in accordance with JCPDS cards 21-1272 and 21-1276. The peaks of $2 \theta$ values at 25.21 and 27.51 can be indexed to the (101) and (110) planes of anatase and rutile titania,
Table 2 Dispersive properties of obtained anode materials

\begin{tabular}{cccc}
\hline Sample & $\begin{array}{l}\text { Range of particle size } \\
\text { distributions by volume } / \mathrm{nm}\end{array}$ & $\begin{array}{l}\text { Maximum volume } \\
\text { contribution/\% }\end{array}$ & Polydispersity index \\
\hline $\mathrm{T}$ & $190-712$ & $396 \mathrm{~nm}-23.7 \%$ & 0.102 \\
$\mathrm{TA}$ & $190-955$ & $459 \mathrm{~nm}-19.0 \%$ & 0.453 \\
$\mathrm{TA} / \mathrm{GO}$ & $295-1110$ & $615 \mathrm{~nm}-6.2 \%$ & 0.405 \\
& $4800-6440$ & $5560 \mathrm{~nm}-36.6 \%$ & \\
\hline
\end{tabular}



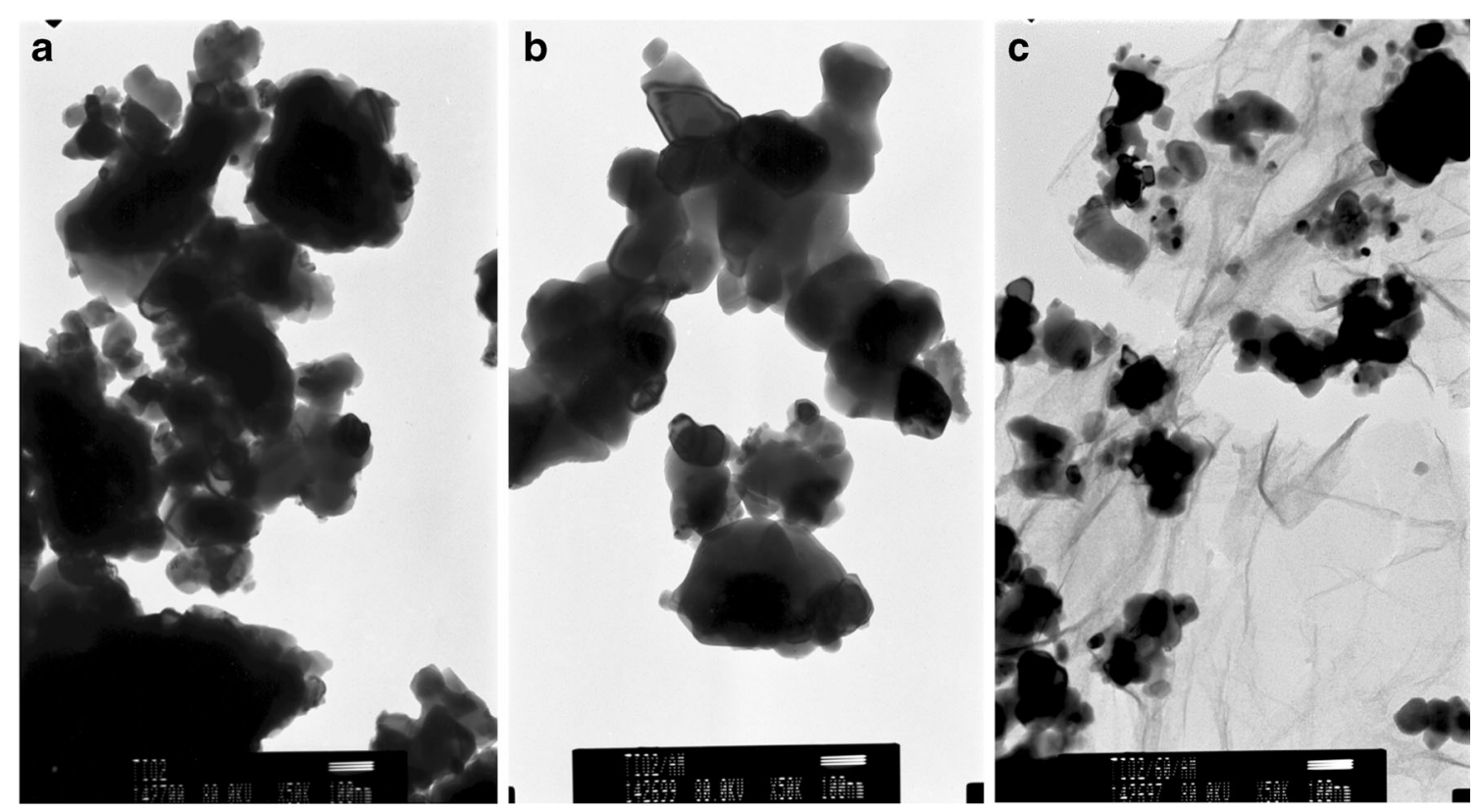

Fig. 2 TEM images of T (a), TA (b), and TA/GO (c)

respectively. The TA/GO composite (Fig. 3b) exhibits similar diffraction peaks corresponding to the native $\mathrm{TiO}_{2}$, meaning that a mixed rutile and anatase crystal phase of titania/ graphene oxide material has been prepared by the hydrothermal process. Only a slight decrease in the intensity of the peak characteristic for anatase at a $2 \theta$ value of 25.21 was observed. This suggests that the addition of graphene oxide and hydrothermal synthesis can lower the temperature of transformation from anatase to rutile. Moreover, no GO peak was observed in the TA/GO composite, because of the relatively low content of $\mathrm{GO}$ in that composite, meaning that GO peaks were masked by the diffraction signals of $\mathrm{TiO}_{2}$ [27]. The crystallite sizes of the $\mathrm{TiO}_{2}$ and $\mathrm{TA} / \mathrm{GO}$ samples were calculated using the

a

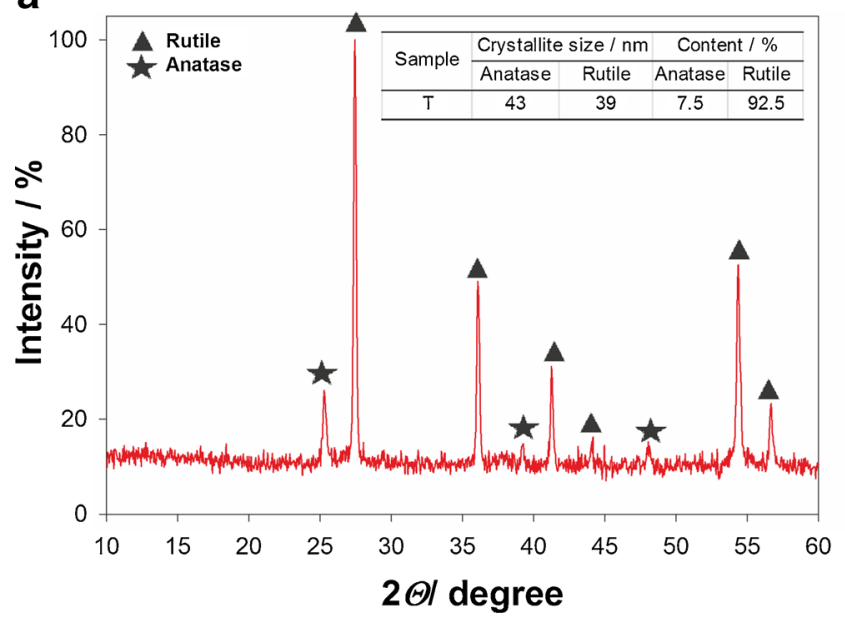

Fig. 3 XRD patterns of the obtained materials
Scherrer equation for the main diffraction peak and relative percentage content of anatase and rutile (see Fig. 3). The sample $T$ is composed of anatase crystallites of $43 \mathrm{~nm}$ and a transformed rutile phase which appears with a crystallite size of approximately $39 \mathrm{~nm}$. The crystallite size of anatase in the $\mathrm{TA} / \mathrm{GO}$ composite is much smaller than that obtained for native $\mathrm{TiO}_{2}(37 \mathrm{~nm})$. This effect is caused by the interaction between $\mathrm{TiO}_{2}$ and $\mathrm{GO}$ [28].

\section{Porous structure parameters}

Surface area, total pore volume, and average pore diameter play an important part in determining the electrochemical

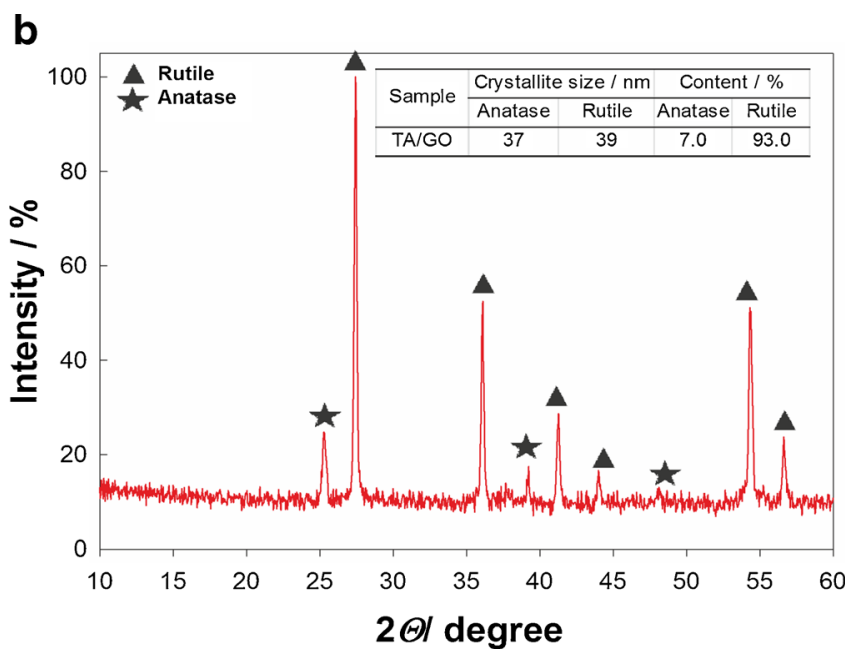


properties of electrode materials [29]. Figure 4 shows the $\mathrm{N}_{2}$ adsorption/desorption isotherms obtained from the physisorption measurements. The isotherms of the obtained materials are identified as type IV, which are characteristic of mesoporous substances. For the synthesized materials, an adsorption and desorption hysteresis loop gradually increases and exhibits an abrupt increase in the high-pressure region, as can be seen from Fig. 4a. This can be associated with capillary condensation and multilayer adsorption of nitrogen in the mesopores. Surface modification of titania with aminosilane leads to a significant decrease in its BET surface area, from 5.0 to $3.8 \mathrm{~m}^{2} \mathrm{~g}^{-1}$. From the adsorption branch of the isotherm curves, a surface area of $6.2 \mathrm{~m}^{2} \mathrm{~g}^{-1}$ is calculated for the TA/GO sample by the multi-point BET method. From the desorption branch of the isotherm curves, a pore volume of $0.022 \mathrm{~cm}^{3} \mathrm{~g}^{-1}$ and mean pore diameter of $17.0 \mathrm{~nm}$ are calculated under the BJH model. The relatively large surface area provided by the TA/GO composite will increase the electrolyte/electrode contact area, which will lead to a decrease in the current density per unit surface area and an increase in the rate performance. Moreover, in the literature, there are samples about the influence of the synthesis method on the electrochemical performance of the LTO spinel. Several samples have been prepared by different synthesis procedures (sol-gel - LTO-SG, self-combustion - LTO CB, and solid state - LTO-SS). They showed the highest capacity, very small surface area BET of $2.48 \mathrm{~m}^{2} \mathrm{~g}^{-1}$, and the particle size in diameter of $301 \mathrm{~nm}$ [30].

\section{FTIR analysis}

Figure 5 shows FTIR spectra of the GO, TA, and TA/GO composite. The FTIR spectrum of graphene oxide contains bands for alkoxy $\mathrm{C}-\mathrm{O}$ stretch $\left(1061 \mathrm{~cm}^{-1}\right)$, epoxy $\mathrm{C}-\mathrm{O}$ stretch $\left(1235 \mathrm{~cm}^{-1}\right)$, aromatic $\mathrm{C}=\mathrm{C}$ and $\mathrm{O}-\mathrm{H}$ bending $\left(1630 \mathrm{~cm}^{-1}\right)$, and $\mathrm{C}=\mathrm{O}$ stretch $\left(1730 \mathrm{~cm}^{-1}\right)$ in carboxylic acid. A broad band in the range $3500-3000 \mathrm{~cm}^{-1}$, which is attributed to the $\mathrm{O}-\mathrm{H}$ stretching frequency from the surface hydroxyls, was also observed. There is also an absorption band at $870 \mathrm{~cm}^{-1}$ related to deformation of aromatic $\mathrm{C}-\mathrm{H}$ bonds and a band at $2854 \mathrm{~cm}^{-1}$ attributed to stretching vibrations of $\mathrm{CH}_{2}$. Meanwhile, the FTIR spectrum of sample TA shows two absorption bands around 515 and $480 \mathrm{~cm}^{-1}$, which correspond to bending and stretching vibrations of $\mathrm{Ti}^{-} \mathrm{O}-\mathrm{Ti}$ bonds. It also shows a characteristic band at around $3400 \mathrm{~cm}^{-1}$, which is due to stretching vibrations of $\mathrm{O}-\mathrm{H}$ as well as $\mathrm{N}-\mathrm{H}$ bonds. The peak observed at $1630 \mathrm{~cm}^{-1}$ originates from the hydroxyl groups of molecular water. In the spectrum of the TA/GO composite, the characteristic absorption bands associated with titania and GO were observed. The absorption bands at 1082 and $1093 \mathrm{~cm}^{-1}$ in the FTIR spectrum of TA/GO can be assigned to vibrations of $\mathrm{Ti}-\mathrm{O}-\mathrm{C}$ bonds. These bands prove the existence of strong chemical interactions between graphene oxide and modified titania in hydrothermal synthesis.

\section{SEM and TEM images of electrodes}

Figure 6 shows SEM images of the pristine TA/GO and TA/ $\mathrm{GO}$ after the intercalation/deintercalation/intercalation process, at different magnifications (TA/GO $1 \mathrm{M} \mathrm{LiPF}_{6}$ in $\mathrm{TMS}+10 \mathrm{wt} . \% \mathrm{VC} \mid \mathrm{Li})$. It can be seen that the electrochemical process in TMS with VC (Fig. 6) leads to changes on the surface of TA/GO particles. However, a similar process in the presence of $\mathrm{VC}$ results in the formation of a coating (SEI) on the surface (Fig. 6). Corresponding TEM images (Fig. 7) also show differences in the surface between pristine TA/GO, after intercalation/deintercalation/intercalation with $0.7 \mathrm{M} \mathrm{LiNTf}_{2}$ a

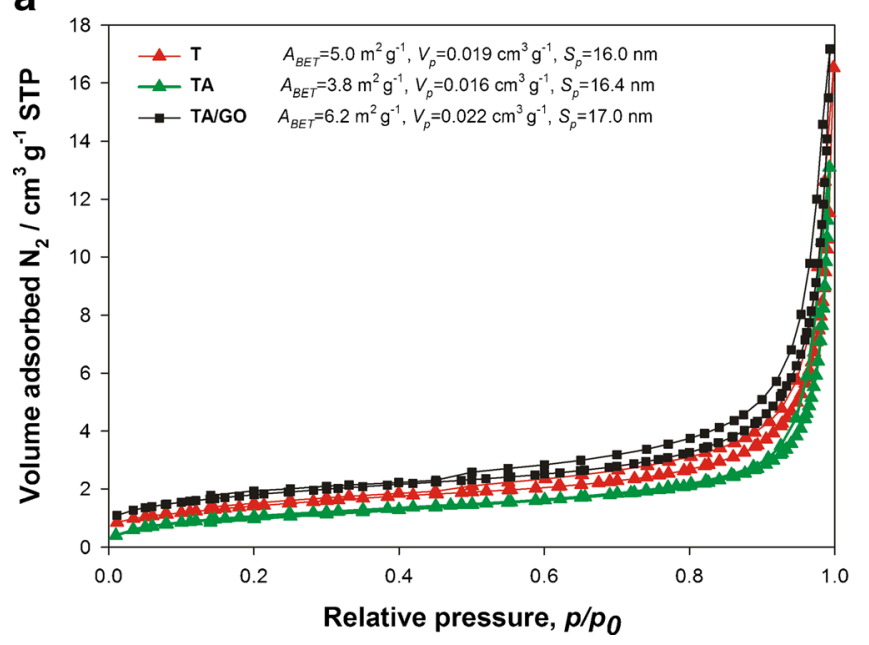

b

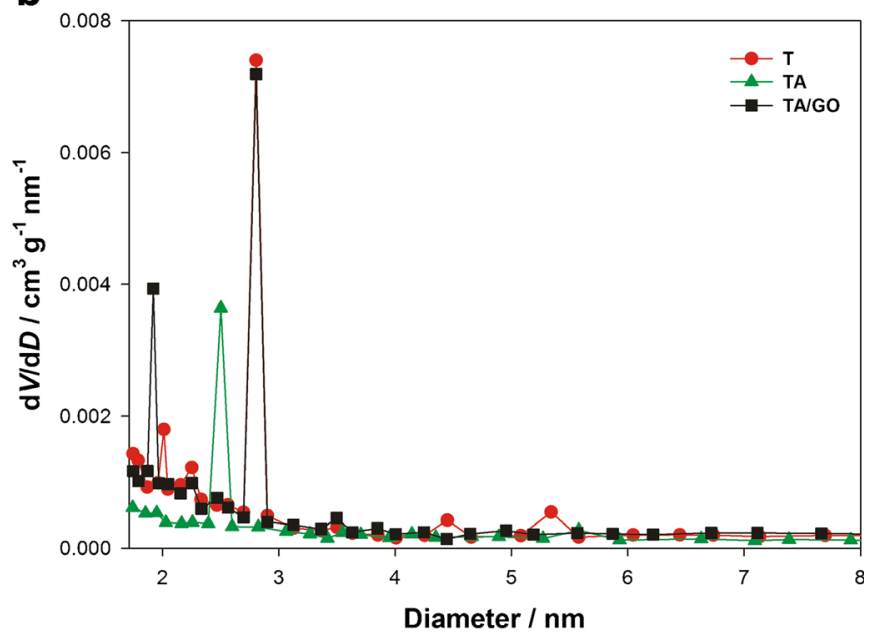

Fig. $4 \mathrm{~N}_{2}$ adsorption/desorption isotherms (a) and pores volume (b) of obtained materials 


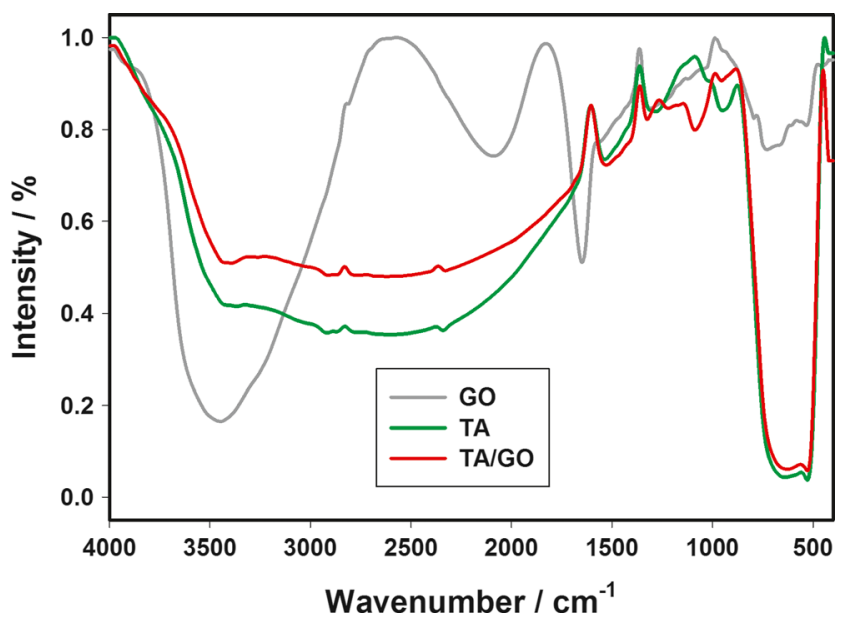

Fig. 5 FTIR spectra of GO, TA, and TA/GO

in MPPyrNTf $2+10$ wt.\% VC (Fig. 7). Again, galvanostatic charging/discharging of the TA/GO material in the electrolyte containing $\mathrm{VC}$ leads to the formation of a deposit on its surface (Fig. 7).

\section{SEI formation}

Anodes characterized by a low potential, such as lithium metal or lithiated graphite, react spontaneously with electrolytes. In the case of lithium metal, the growth of dendrite crystals on its surface is observed. It has also been shown that lithiated graphite requires the formation of a protective coating, similarly to metallic lithium. Consequently, the electrolyte for Liion batteries is expected to form SEI, protecting the lithium anode [31]. A similar phenomenon was also found for the TA/ $\mathrm{GO}$ anode. A solid electrolyte interface can be formed on the TA/GO anode after several cycles. This is different in the case
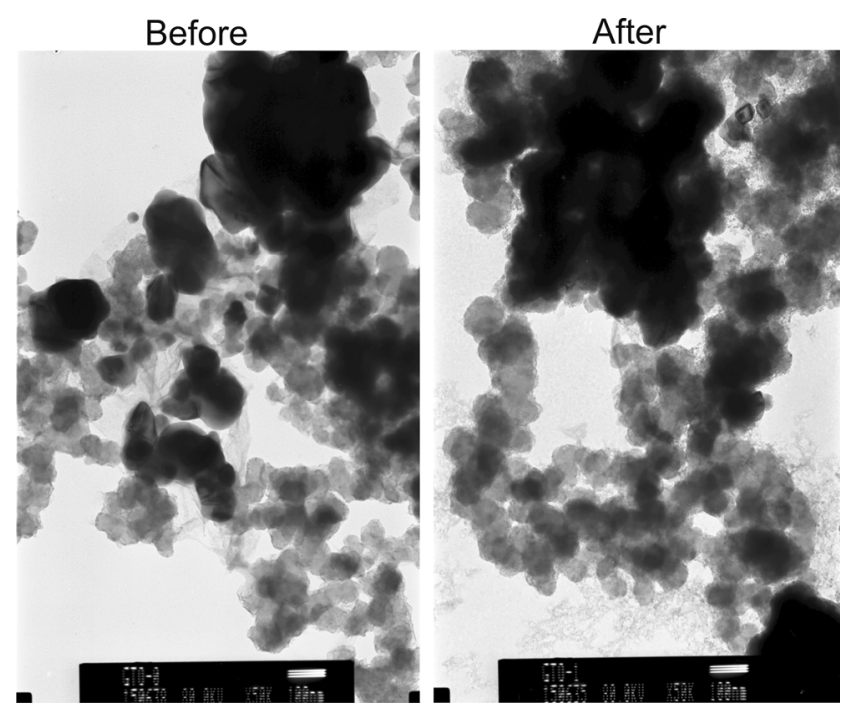

Fig. 7 TEM images of the TA/GO electrode before and after charging/ discharging (100 cycles - TA/GO| 0.7 $\mathrm{M} \mathrm{LiNTf}_{2}$ in $\mathrm{MPPyrNTf}_{2}+10$ wt.\% VC $\mid \mathrm{Li})$

of a graphite anode, where the SEI film forms during the initial cycle $[32,33]$. The passivation of electrodes in a Li-ion battery may be observed with the help of impedance spectroscopy. Electrochemical impedance spectra (EIS) of the TA/ GO $\mid$ electrolyte $\mid$ Li were measured before discharge and after 20 cycles. The semicircle can be attributed to phenomena such as polarization resistance and the formation of the SEI layer.

Figure 8 shows the Nyquist plots of TA/GO samples in IL and TMS. Generally, the diameter of the quasisemicircle is associated with the charge transfer resistance $\left(R_{c t}\right)$. A lower $R_{c t}$ will be beneficial in improving the electrochemical dynamical behavior. The TA/ GO sample in IL has the smallest $R_{c t}$, due to its good electric conductivity compared with TA/GO in TMS.
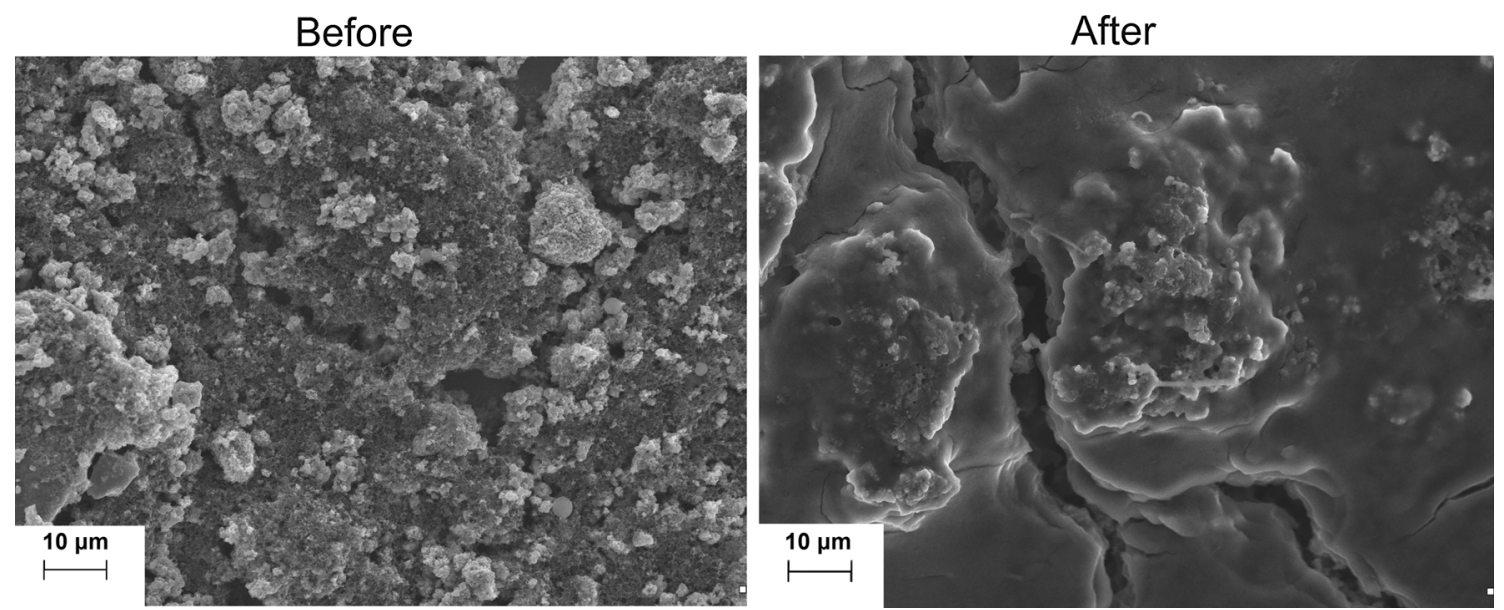

Fig. 6 SEM images of the TA/GO electrode before and after charging/discharging (100 cycles - TA/GO| 1 M LiPF 6 in TMS + 10 wt. $\%$ VC $\mid \mathrm{Li})$ 


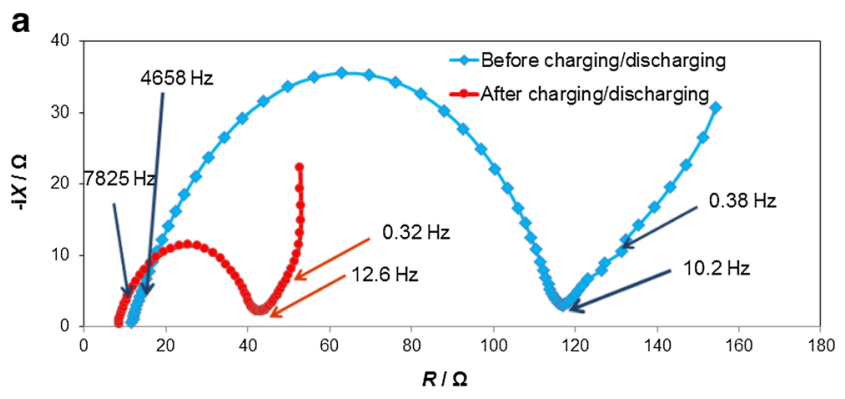

b

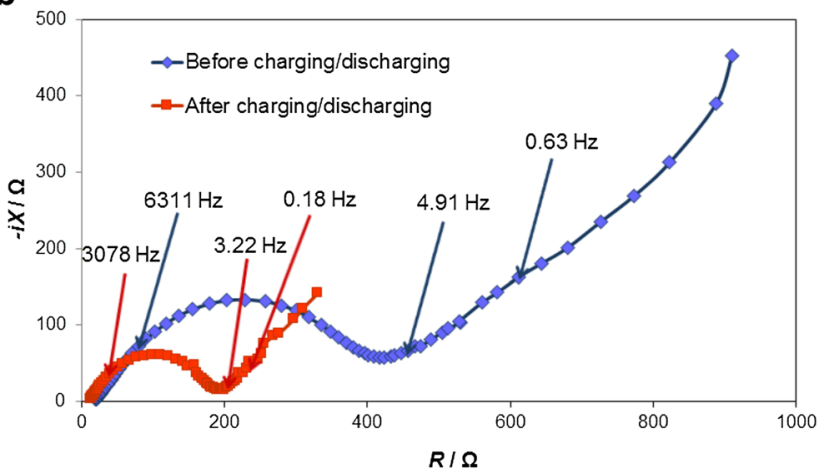

c

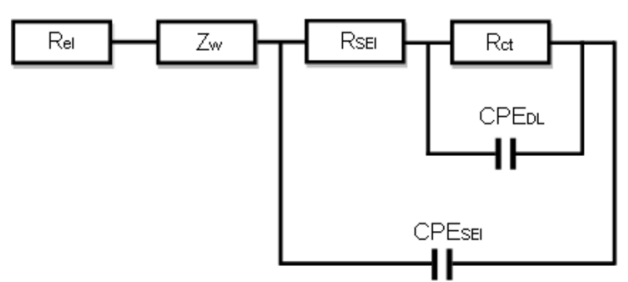

Fig. 8 Impedance spectroscopy of the TA/GO| $0.7 \mathrm{M} \mathrm{LiNTf}_{2}$ in MPPyrNTf $_{2}+10$ wt. $\%$ VC cell (a), TA/GO $1 \mathrm{M} \mathrm{LiPF}_{6}$ in TMS + 10 wt.\% VC | Li cell (b), and an equivalent representing the electrode/ electrolyte system (c)

Both of the systems (TA/GO| TMS $\mid \mathrm{Li}$ and TA/ $\mathrm{GO}|\mathrm{IL}| \mathrm{Li})$ have one semicircle in the high-frequency range and a sloping straight line in the low-frequency range. As shown in Fig. 8, the radius of the semicircle of the mesoporous TA/GO composite electrode in IL (Fig. 8a) is significantly smaller than that of the blank TA/GO composite electrode in TMS (Fig. 8b), suggesting that the charge transfer resistance of the TA/GO composite sample in IL is lower than that of the TA/GO in TMS. This suggests that conductive graphene oxide in the composite can facilitate electron transfer and contribute to the higher rate capability of the TA/GO composite electrode.

\section{Cyclic voltammetry}

Figure 9 shows the initial $C V$ curves of the mesoporous composite, modified $\mathrm{TiO}_{2}$, and blank $\mathrm{TiO}_{2}$. For the blank $\mathrm{TiO}_{2}$, there is a pair of cathodic/anodic peaks centered at 1.60 and $2.1 \mathrm{~V}$, corresponding respectively to lithium insertion/ extraction in the anatase $\mathrm{TiO}_{2}$ lattice [34]. Compared with the mesoporous composite, the blank $\mathrm{TiO}_{2}$ has sharper peaks, a

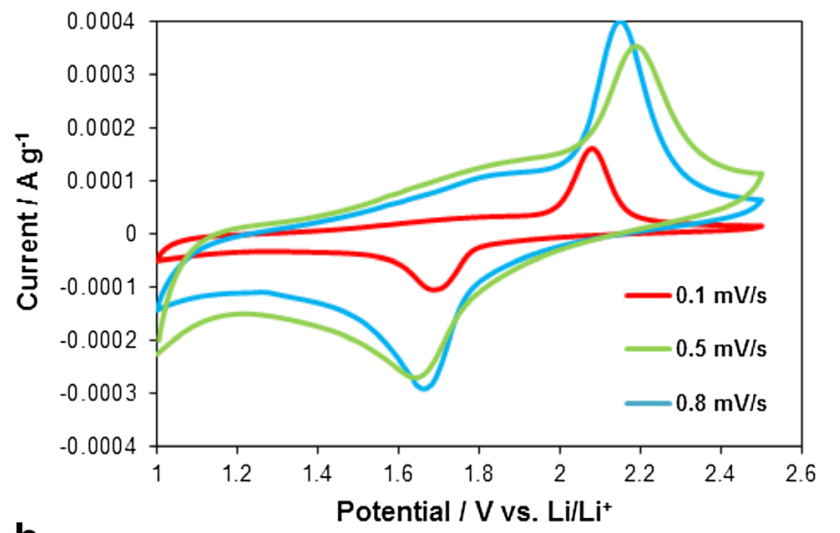

b

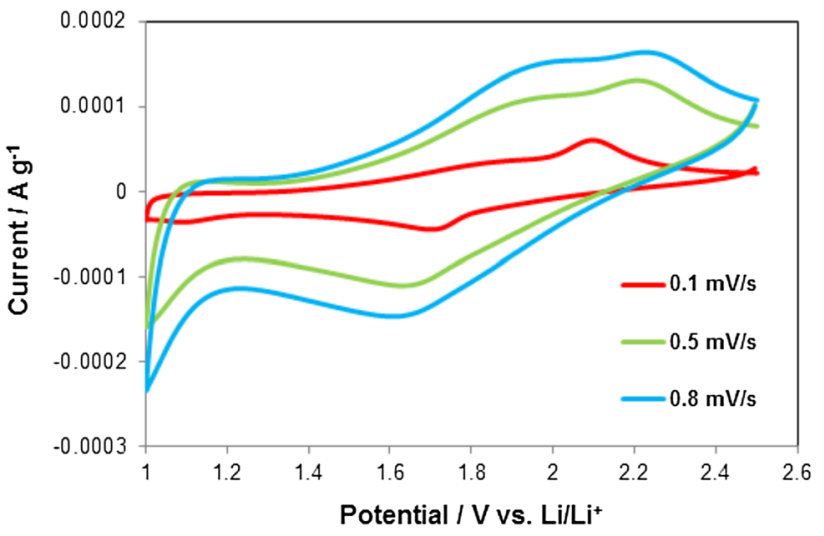

C

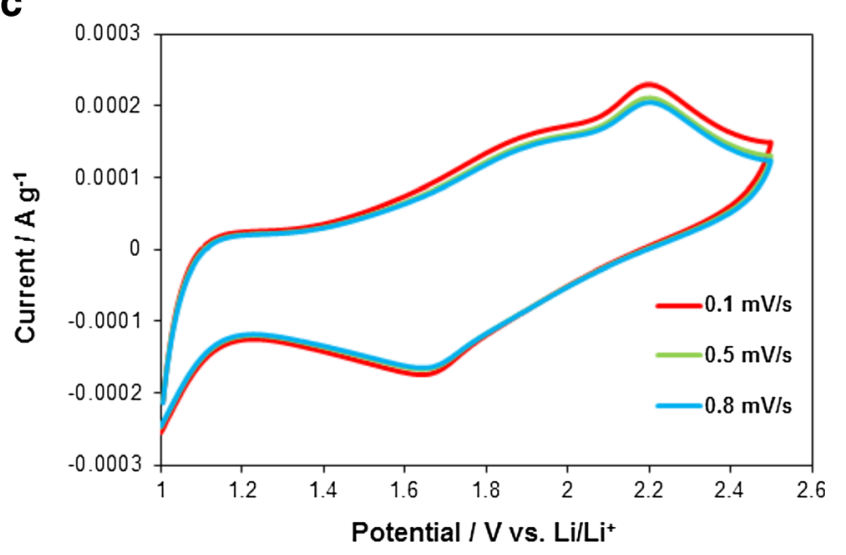

Fig. $9 \mathrm{CVs}$ of the $\mathrm{TiO}_{2}(\mathbf{a}), \mathrm{TA}(\mathbf{b})$, and TA/GO (c) at different scan rates

higher peak currents, and a narrower potential gap between these two redox peaks, suggesting that the blank $\mathrm{TiO}_{2}$ offers somewhat better kinetics for Li-ion insertion and extraction. In contrast to conventional anatase $\mathrm{TiO}_{2}$, another obvious peak appearing around $1.52 \mathrm{~V}$ can be observed for the composite, which is attributed to the faradic pseudo-capacitive process.

To further investigate the pseudo-capacitive contribution, $C V$ s of the TA/GO composite at different scan rates were performed and analyzed (Fig. 9). The titanium dioxide after modification has less clear peaks (Fig. 9b).

The enhanced pseudo-capacitive effect for the composite further confirmed the strong interactions between the 
graphene oxide and $\mathrm{TiO}_{2}$, as the binding of $\mathrm{TiO}_{2}$ nanoparticles on the graphene oxide can produce abundant interfaces, which can offer extra lithium storage and thus lead to an obvious current peak in the cathodic process $[13,35,36]$.

\section{Charging/discharging tests}

To indicate the discharge/charge capacity and cycle stability of the mesoporous composite, the variation of discharge capacity with cycles at increasing current densities from 5 to $50 \mathrm{~mA} \mathrm{~g}^{-1}$ applied successively is presented in Fig. 10. A discharge capacity of ca. $245 \mathrm{mAh} \mathrm{g}^{-1}$ is obtained after the 10th cycle at a current density of $5 \mathrm{~mA} \mathrm{~g}^{-1}$, and this value is reduced to 191 , $210,195,176$, and $153 \mathrm{mAh} \mathrm{g}^{-1}$ at current densities of 5, 10, 20,30 , and $50 \mathrm{~mA} \mathrm{~g}^{-1}$, respectively (TA/GO| $0.7 \mathrm{M} \mathrm{LiNTf}_{2}$ in $\mathrm{MPPyrNTf}_{2}+10$ wt.\% VC| Li, Fig. 10a). More importantly, after 100 cycles at successively increasing current densities, the as-prepared composite can still demonstrate an impressive discharge capacity of $240 \mathrm{mAh} \mathrm{g}^{-1}$ at a current density of $5 \mathrm{~mA} \mathrm{~g}^{-1}$ for another 30 cycles. Similar stable cycle performance can be observed for TA/GO| $1 \mathrm{M} \mathrm{LiPF}_{6}$ in TMS +10 wt.\% VC| Li systems for the initial 70 cycles, but this has a low discharge capacity of $210 \mathrm{mAh} \mathrm{g}^{-1}$ at the high current of $5 \mathrm{~mA} \mathrm{~g}^{-1}$. Additionally, when the current is further increased to $50 \mathrm{~mA} \mathrm{~g}^{-1}$ after 100 cycles, the TA/GO composite still presents a stable cycle performance, but the discharge capacity of TA/GO $1 \mathrm{M} \mathrm{LiPF}_{6}$ in TMS +10 wt.\% VC| Li significantly decreases (for $50 \mathrm{~mA} \mathrm{~g}^{-1}$, it was $140 \mathrm{mAh} \mathrm{g}^{-1}$ ). Therefore, the as-prepared composite can endure significant changes of low or high current densities and yet retain good stability upon cycling, and this is advantageous for abuse tolerance of LIBs with high power and long cycle life. The $\mathrm{TiO}_{2} / \mathrm{GO}$ composite anode displayed a stable cycle performance and retained a high discharge capacity in both TA/GO IL $\mid \mathrm{Li}$ and TA/GO $|\mathrm{TMS}| \mathrm{Li}$ after the 100th cycle, which so far represents the highest capacity at such high current density in comparison with the $\mathrm{TiO}_{2}$ /graphene composites reported in the literature [37-44].

\section{Conclusions}

Galvanostatic charging/discharging, CV, EIS, and SEM show that the lithium intercalation and deintercalation process occurs quite reversibly in TA/GO materials with good cycling stability. SEM images of pristine electrodes and those taken after electrochemical cycling show changes which may be interpreted as resulting from SEI formation.

Charge/discharge tests of TA/GO $\mid \mathrm{Li}$ cells indicate that the reversible capacity for TA/GO| $0.7 \mathrm{M} \mathrm{LiNTf}_{2}$ in MPPyrNTf $_{2}+10 \mathrm{wt} . \% \mathrm{VC} \mid \mathrm{Li}$ is $215 \mathrm{mAh} \mathrm{g}^{-1}$ at a current density of $10 \mathrm{mAh} \mathrm{g}^{-1}$, while for TA/GO| $1 \mathrm{M} \mathrm{LiPF}_{6}$ in $\mathrm{TMS}+10 \mathrm{wt} . \% \mathrm{VC} \mid \mathrm{Li}$ the value is $189 \mathrm{mAh} \mathrm{g}^{-1}$.
Fig. 10 Rate performance under various current densities: TA/ $\mathrm{GO} \mid 0.7 \mathrm{M} \mathrm{LiNTf}_{2}$ in MPPyrNTf $_{2}+10$ wt. $\% \mathrm{VC} \mid \mathrm{Li}$ (a) and TA/GO $1 \mathrm{M} \mathrm{LiPF}_{6}$ in TMS + 10 wt. $\%$ VC| Li (b)

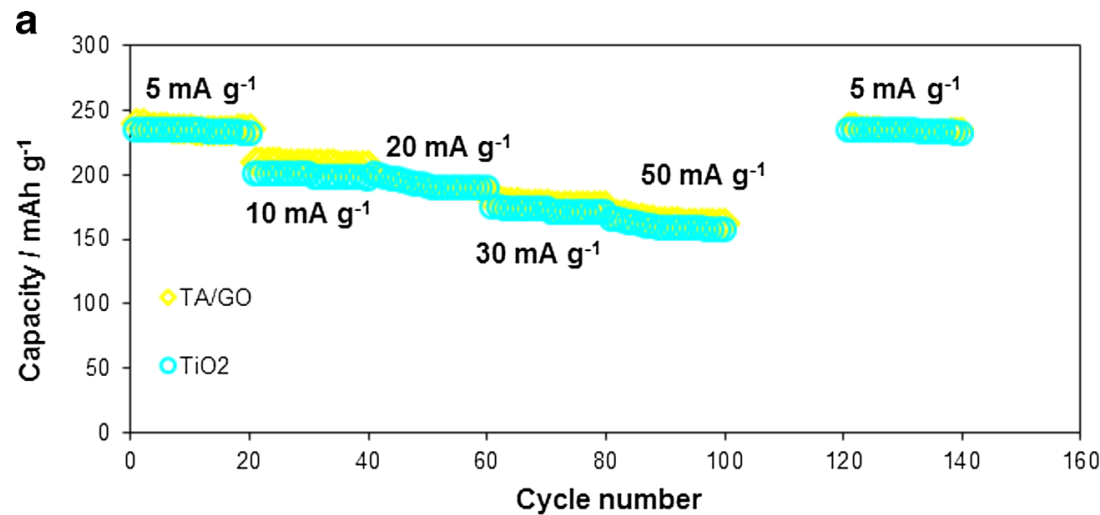

b

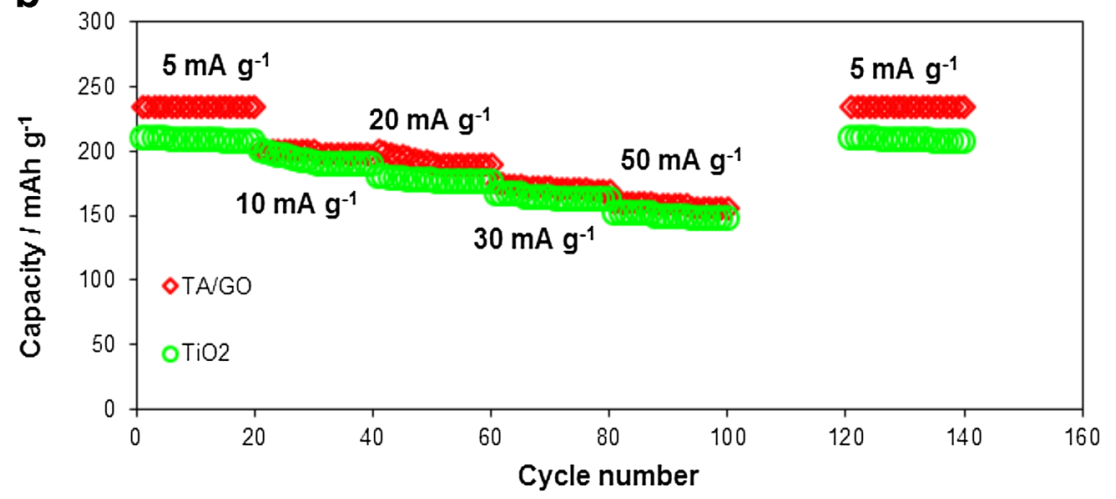


All of the results obtained show that the activated TA/GO composite anode demonstrates a good cycle life capability in combination with sulfolane (TMS) and ionic liquid (MePrPyrNTf $)_{2}$ electrolyte.

Acknowledgments This work was supported by Poznan University of Technology research grant nos. 03/31/DSMK/0301/2015 and 03/32/ DSPB/0606/2016.

Open Access This article is distributed under the terms of the Creative Commons Attribution 4.0 International License (http:// creativecommons.org/licenses/by/4.0/), which permits unrestricted use, distribution, and reproduction in any medium, provided you give appropriate credit to the original author(s) and the source, provide a link to the Creative Commons license, and indicate if changes were made.

\section{References}

1. Zhen M, Guo S, Gao G, Zhou Z, Liu L (2015) $\mathrm{TiO}_{2}$-B nanorods on reduced graphene oxide as anode materials for $\mathrm{Li}$ ion batteries. Chem Comm 51:507-510

2. Wang C, Li H, Fu A, Liu J, Ye W, Guo P, Pang G, Zhao S (2014) An RAPET approach to in situ synthesis of carbon modified $\mathrm{Li}_{4} \mathrm{Ti}_{5} \mathrm{O}_{12}$ anode nanocrystals with improved conductivity. New J Chem 38: 616-623

3. Wang J, Shen L, Li H, Wang X, Nie P, Ding B, Xu G, Dou H, Zhang $\mathrm{X}$ (2014) A facile one-pot synthesis of $\mathrm{TiO}_{2}$ /nitrogen-doped reduced graphene oxide nanocomposite as anode materials for highrate lithium-ion batteries. Electrochim Acta 133:209-216

4. Sheha E (2014) Studies on $\mathrm{TiO}_{2} /$ reduced graphene oxide composites as cathode materials for magnesium-ion battery. Graphene 3: 36-43

5. Zhu Q, Hu H, Li G, Zhu Ch YY (2015) $\mathrm{TiO}_{2}$ nanotube arrays grafted with $\mathrm{MnO}_{2}$ nanosheets as high-performance anode for lithium ion battery. Electrochim Acta 156:252-260

6. Kim JH, Kang Y, Kim D-W (2012) Cycling performance of $\mathrm{Li}_{4} \mathrm{Ti}_{5} \mathrm{O}_{12}$ electrodes in ionic liquid-based gel polymer electrolytes. Bull Kor Chem Soc 33:608-612

7. Uchaker E, Cao G (2014) Mesocrystals as electrode materials for lithium-ion batteries. Nano Today 9:499-524

8. Liu S, Zhu K, Tian J, Zhang W, Bai S, Shan Z (2015) Submicronsized mesoporous anatase $\mathrm{TiO}_{2}$ beads with trapped $\mathrm{SnO}_{2}$ for longterm, high-rate lithium storage. J Alloys Comp 639:60-67

9. Świderska-Mocek A (2014) Electrolyte based on 1-ethyl-3vinylimidazolium bis(trifluoromethanesulphonyl)imide for Li-ion batteries. Electrochim Acta 132:504-511

10. Li Y, Wang Z, Lv X-J (2014) N-doped $\mathrm{TiO}_{2}$ nanotubes/N-doped graphene nanosheets composites as high performance anode materials in lithium-ion battery. J Mater Chem A 2:15473-15479

11. Tang H, Zhang J, Zhang YJ, Xiong QQ, Tong YY, Li Y, Wang XL, $\mathrm{Gu}$ CD, Tu JP (2015) Porous reduced graphene oxide sheet wrapped silicon composite fabricated by steam etching for lithium-ion battery application. J Power Sources 286:431-437

12. Wang X, Wang Y, Yang L, Wang K, Lou X, Cai B (2014) Templatefree synthesis of homogeneous yolk-shell $\mathrm{TiO}_{2}$ hierarchical microspheres for high performance lithium ion batteries. J Power Sources 262:72-78

13. Zhang X, Kumar PS, Aravindan V, Liu HH, Sundaramurthy J, Mhaisalkar SG, Duong HM, Ramakrishna S, Madhavi S (2012) Electrospun $\mathrm{TiO}_{2}$-graphene composite nanofibers as a highly durable insertion anode for lithium ion batteries. J Phys Chem C 116: 14780-14788
14. Zhao N, Li T, Jiao L, Qi Y-X, Zhu H-L, Liu J-R, Fan R-H, Lun N, Bai Y-J (2015) Enhancing the comprehensive electrochemical performance by compositing intercalation/deintercalation-type of $\mathrm{TiO}_{2}$ with conversion-type of MnO. J Alloys Comp 640:15-22

15. Dong L, Li M, Dong L, Zhao M, Feng J, Han Y, Deng J, Li X, Li D, Sun X (2014) Hydrothermal synthesis of mixed crystal phases $\mathrm{TiO}_{2}$-reduced graphene oxide nanocomposites with small particle size for lithium ion batteries. Int J Hydrog Energy 39:16116-16122

16. Yun YS, Le V-D, Kim H, Chang S-J, Baek SJ, Park S, Kim BH, Kim Y-H, Kang K, Jin H-J (2014) Effects of sulfur doping on graphene-based nanosheets for use as anode materials in lithiumion batteries. J Power Sources 262:79-85

17. Tang Y-P, Wang S-M, Tan X-X, Hou G-Y, Zheng G-Q (2014) $\mathrm{TiO}_{2} /$ graphene nanocomposites as anode materials for high rate lithiumion batteries. J Cent South Univ 21:1714-1718

18. Qiu J, Zhang P, Ling M, Li S, Liu P, Zhao H, Zhang S (2012) Photocatalytic synthesis of $\mathrm{TiO}_{2}$ and reduced graphene oxide nanocomposite for lithium ion battery. ACS Appl Mater Interfaces 4: 3636-3642

19. Di Lupo F, Tuel A, Mendez V, Francia C, Meligrana G, Bodoardo $\mathrm{S}$, Gerbaldi C (2014) Mesoporous $\mathrm{TiO}_{2}$ nanocrystals produced by a fast hydrolytic process as high-rate long-lasting Li-ion battery anodes. Acta Mater 69:60-67

20. Inaba M, Oba Y, Niina F, Murota Y, Ogino Y, Tasaka A, Hirota K (2009) $\mathrm{TiO}_{2}$ (B) as a promising high negative electrode fir large-size lithium-ion batteries. J Power Sources 189:580-584

21. Xiu Z, Hao X, Wu Y, Lu Q, Liu S (2015) Graphene-bonded and encapsulated mesoporous $\mathrm{TiO}_{2}$ microspheres as a highperformance anode material for lithium ion batteries. J Power Sources 287:334-340

22. Li D, Shi D, Liu Z, Liu H, Guo Z (2013) $\mathrm{TiO}_{2}$ nanoparticles on nitrogen-doped graphene as anode material for lithium ion batteries. J Nanoparticle Res 15:1674-1683

23. Siwińska-Stefańska K, Paukszta D, Piasecki A, Jesionowski T (2014) Synthesis and physicochemical characteristic of titanium dioxide doped with selected metals. Physicochem Probl Miner Process 50:265-276

24. Siwińska-Stefańska K, Ciesielczyk F, Nowacka M (2012) Jesionowski T (2012) Influence of selected alkoxysilanes on dispersive properties and surface chemistry of titanium dioxide and $\mathrm{TiO}_{2-}$ $\mathrm{SiO}_{2}$ composite material. J Nanomater. doi:10.1155/2012/316173

25. Nowacka M, Siwińska-Stefańska K, Jesionowski T (2013) Structural characterisation of titania or silane-grafted $\mathrm{TiO}_{2}-\mathrm{SiO}_{2}$ oxide composite and influence of ionic strenght or electrolyte type on their elecktokinetic properties. Colloid Polym Sci 291:603-612

26. Cullity BD (1978) Elements of X-ray diffraction. Addison Wesley Publishing Company Inc., Menlo Park

27. Kumar R, Singh RK, Dubey PK, Singh DP, Yadav RM, Tiwari RS (2015) Hydrothermal synthesis of a uniformly dispersed hybrid graphene- $\mathrm{TiO}_{2}$ nanostructure for optical and enhanced electrochemical applications. RSC Adv 5:7112-7120

28. Liu R, Guo W, Sun B, Pang J, Pei M, Zhou G (2015) Composites of rutile $\mathrm{TiO}_{2}$ nanorods loaded on graphene oxide nanosheet with enhanced electrochemical performance. Electrochim Acta 156: 274-282

29. Xiang C, Li M, Zhi M, Manivannan A, Wu N (2012) Reduced graphene oxide/titanium dioxide composites for supercapacitor electrodes: shape and coupling effects. J Mater Chem 22:19161-19167

30. Mahmoud A, Amarilla JM, Lasri K, Saadoune I (2013) Influence of the synthesis method on the electrochemical properties of the $\mathrm{Li}_{4} \mathrm{Ti}_{5} \mathrm{O}_{12}$ spinel in Li-half and Li-ion full-cells. A systematic comparison. Electrochim Acta 93:163-172

31. Ding Y, Li GR, Xiao CW, Gao XP (2013) Insight into effects of graphene in $\mathrm{Li}_{4} \mathrm{Ti}_{5} \mathrm{O}_{12} /$ carbon composite with high rate capability as anode materials for lithium ion batteries. Electrochim Acta 102: 282-289 
32. Shu J (2008) Study of the interface between $\mathrm{Li}_{4} \mathrm{Ti}_{5} \mathrm{O}_{12}$ electrodes and standard electrolyte solutions in 0.0-5.0 V. Electrochem Solid State Lett 11:A238-A240

33. Wu F, Wang Z, Li X, Wu L, Wang X, Zhang X, Wang Z, Xiong X, Guo $\mathrm{H}$ (2011) Preparation and characterization of spinel $\mathrm{Li}_{4} \mathrm{Ti}_{5} \mathrm{O}_{12}$ anode material from industrial titanyl sulfate solution. J Alloys Compd 509:596-601

34. Zhou X, Wan L-J, Guo Y-G (2013) Binding $\mathrm{SnO}_{2}$ nanocrystals in nitrogen-doped graphene sheets as anode materials for lithium-ion batteries. Adv Mater 25:2152-2157

35. Shin J-Y, Samuelis D, Maier J (2011) Sustained lithium-storage performance of hierarchical, nanoporous anatase $\mathrm{TiO}_{2}$ at high rates: emphasis on interfacial storage phenomena. Adv Funct Mater 21: 3464-3472

36. Wang J, Polleux J, Lim J, Dunn B (2007) Pseudocapacitive contributions to electrochemical energy storage in $\mathrm{TiO}_{2}$ (anatase) nanoparticles. J Phys Chem C 111:14925-14931

37. Cao H, Li B, Zhang J, Lian F, Kong X, Qu M (2012) Synthesis and superior anode performance of $\mathrm{TiO}_{2} @$ reduced graphene oxide nanocomposites for lithium ion batteries. J Mater Chem 22:9759-9766

38. Li W, Wang F, Feng S, Wang J, Sun Z, Li B, Li Y, Yang J, Elzatahry AA, Xia Y, Zhao D (2013) Sol-gel design strategy for ultradispersed
$\mathrm{TiO}_{2}$ nanoparticles on graphene for high-performance lithium ion batteries. J Am Chem Soc 135:18300-18303

39. Li N, Liu G, Zhen C, Li F, Zhang L, Cheng H-M (2011) Battery performance and photocatalytic activity of mesoporous anatase $\mathrm{TiO}_{2}$ nanospheres/graphene composites by template-free self-assembly. Adv Funct Mater 21:1717-1722

40. Shen L, Zhang X, Li H, Yuan C, Cao G (2011) Design and tailoring of a three dimensional $\mathrm{TiO}_{2}$-graphene-carbon nanotube nanocomposite for fast lithium storage. J Phys Chem Lett 2:3096-3101

41. Ding S, Chen JS, Luan D, Boey FYC, Madhavi S, Lou XW (2011) Graphene supported anatase $\mathrm{TiO}_{2}$ nanosheets for fast lithium storage. Chem Commun 47:5780-5782

42. Yang S, Feng X, Müllen K (2011) Sandwich-like, graphene-based titania nanosheets with high surface area for fast lithium storage. Adv Mater 23:3575-3579

43. Xin X, Zhou X, Wu J, Yao X, Liu Z (2012) Scalable synthesis of $\mathrm{TiO}_{2} /$ graphene nanostructured composite with highrate performance for lithium ion batteries. ACS Nano 6: $11035-11043$

44. Martinmaa J, Lagowski JJ (1976) Sulfolane in the chemistry of nonaqueous solvents. Academic Press, New York 